\title{
Korea's Robotland: Merging Intelligent Robotics Strategic Policy, Business Development, and Fun
}

\author{
Eugene Jun \\ Incheon IT Industry Promotion Agency, 20F. Incheon IT Tower, 592-5, Dowha 1 Dong, \\ Namgu, Incheon City, Korea, 402-711, \\ rightjun@iitpa.or.kr, sciencejun@yahoo.co.kr
}

\begin{abstract}
South Korea specializes in the design and manufacture of service and entertainment robots for consumer use. The government of South Korea considers robotics one of the countries main growth industries. To boost robot industry and accelerate the social demand of intelligent robots, a theme park titled 'Robotland' is being constructed in Korea near Incheon International airport, the gateway to Seoul. A total of $\$ 700$ million will be invested by the Korean government, the city of Incheon and financial investors. The 760,000 square meter site (188 acres) will contains a number of displays featuring famous robots and robot characters from around the world. Ultra-modern rides and amusement facilities, exhibition halls, shopping arcades and hotels, featuring advanced ubiquitous environments, will also be included in the park. In addition, Robotland will contain R\&D centers and educational institutions. The Grand opening is scheduled in 2012. In this session, attendees will hear of development plans for Robotland, along with the social and business issues that are driving the development of the world's first theme park.
\end{abstract}

Keywords: Lobotland, Robot, Teme park, Incheon, URC. 